\title{
Pemphigus vulgaris with squamous cell carcinoma of the tongue: An uncommon association
}

\section{Gandikota Raghu Rama Rao1, Nutakki Rama Koteswara Rao², Manthena Sridevi, Asapu Amareswar ${ }^{3}$, Arumilli Prasad Chowdary ${ }^{1}$}

${ }^{1}$ Department of Dermatology Venerology Leprology, GSL Medical College, Rajhamundry, Rajahmundry-533296, Andhra Pradesh, India, ${ }^{2}$ Department of Pathology, GSL Medical College, Rajhamundry, Rajahmundry-533296, Andhra Pradesh, India, ${ }^{3}$ Consultant Dermatologist, Surya Skin Care and Research Center, Visakhapatnam, India

Corresponding author: Dr. Gandikota Raghu Rama Rao, E-mail: graghuramarao@gmail.com

\begin{abstract}
Pemphigus Vulgaris (PV) is an autoimmune blistering disease wherein, many keratinocyte adhesion molecules (desmogleins) are targets of circulating autoantibodies like anti desmoglein 3 (DSG3) and desmoglein 1 (DSGl) antibodies. DSG3 appears to be of primary importance in maintaining the integrity of oral epithelium. It is targeted in pemphigus vulgaris and paraneoplastic pemphigus with severe oral involvement. DSGl, on the other hand is essential for the integrity of non-mucosal skin surface. Recent studies have shown that desmosomes are not merely static structures but may also play an important role in the regulation of cell-proliferation, apoptosis and migration. Thus, desmosomes have a potential role in cancer development can be hypothesized. Cases of PV with systemic malignancies have been reported frequently but PV with cancers of oral cavity and tongue are rarely reported. The link between PV and malignancy still needs to be elucidated. We report a 35-year-old man with PV in whom Squamous Cell Carcinoma of the tongue developed subsequently. We tried to explore the role of antidesmosomal antibodies for association of these two conditions with the help of the available literature.
\end{abstract}

Key words: Pemphigus vulgaris; Squamous cell carcinoma of tongue; Desmosomes; Antidesmosomal antibodies

\section{INTRODUCTION}

Pemphigus Vulgaris (PV) is an autoimmune blistering disease with circulating anti desmoglein 3 (DSG3) and desmoglein 1 (DSGl) antibodies, targetting intercellular adhesion molecules, desmosomes. PVwith cancers of oral cavity and tongue is uncommon and rarely reported [1-4]. The link between PV and malignancy still needs to be elucidated.We describe a patient with pemphigus vulgaris in whom Squamous Cell Carcinoma (SCC) of the tongue subsequently developed.

\section{CASE REPORT}

A 35-year-old non-diabeticman, with pemphigus vulgaris of 2 years duration on systemic steroids, was referred to us for Dexamethasone-Cyclophosphamide Pulse (DCP) therapy. He had multiple flaccid blisters over the face, axillae, and the body with extensive ulcerations and erosions of oral mucosa and tongue. In addition, there was a large vegetative, cauliflowerlike growth over the right lateral margin of the tongue (Fig. la and b). Clinical history revealed that the patient initially developed oral lesions, followed by cutaneous blisters two years ago and consulted a dermatologist. A diagnosis of pemphigus vulgaris was made and has been on systemic steroids since then. He observed a small growth on the right lateral margin of the tongue six months ago. The growth gradually increased in size and attained the present form. There was no regional lymphadenopathy and systemic examination was normal. Patient was non-smoker, non-alcoholic and was not in the habit of chewing tobacco or betel nut. We suspected

\footnotetext{
How to cite this article: Rama Rao GR, Koteswara Rao NR, Sridevi M, Amareswar A, Chowdary AP. Pemphigus vulgaris with squamous cell carcinoma of the tongue: An uncommon association. Our Dermatol Online. 2017;8(3):286-288.

Submission: 13.10.2016; Acceptance: 13.04.2017

DOI: 10.7241 /ourd.20173.82
} 
squamous cell carcinoma of the tongue and took biopsies from the growth and also from the cutaneous lesions. Histopathological and immunofluorescence studies of cutaneous lesions were consistent with pemphigus vulgaris (Fig. 2a and b). Biopsy from the tongue growth revealed well-differentiated squamous cell carcinoma (Fig. 3).Enzyme-linked immunosorbent assay (ELISA) detectedserum anti DSG3 and DSG1 antibodies. All relevant hematological and biochemical tests were within normal limits. Ultrasound abdomen and radiograph of chest were normal. He was referred to a surgical oncologist for further management. He did not report to us subsequently.

\section{DISCUSSION}

This rare case has prompted us to study and ascertain if these two conditions are just coincidental or related. Do antidesmosomal antibodies play a role in carcinogenesis? Recent studies [5,6] have shown that the desmosomes are not merely static structural entities. They may play an important role in the regulation of cell proliferation, apoptosis and migration. Consequently, a potential role of desmosomes in cancer development can be hypothesized. Although an understanding of the role of desmosomes in cancer is still evolving, human cancer expression data and functional studies on cultured cells suggest that desmosomes normally function as tumor suppressive complexes and that loss of desmosome proteins and desmosome-mediated adhesins is associated with cancer development and progression [6]. But there are divergent hypotheses concerning the role of DSG3 in tumor aggressiveness. There are several studies reporting the increased expression of DSG1 and DSG 3 in squamous cell carcinoma of the soft palate [7], and DSG3 in head and neck squamous cell carcinoma [8] or conversely decreased expression of desmocollin 3 and DSG3 in oral squamous cell carcinoma [9]. There is one study describing decrease of desmoplakin and plakophilin-l in dysplastic and oral squamous cell carcinoma [10]. In another recent study, the authors were of the opinion that antibodies against desmocollins and subsequent loss of keratinocytes adhesion might be the linking facts for squamous cell carcinoma and pemphigus [3]. Furthermore, DSG3 was reported as a biomarker of occult lymph node metastasis in oral cancer [11]. All the data suggest that the mechanism by which desmosomes induced carcinogenesis is unclear, but altered expression of desmosome proteins might promote cancer development in certain contexts.

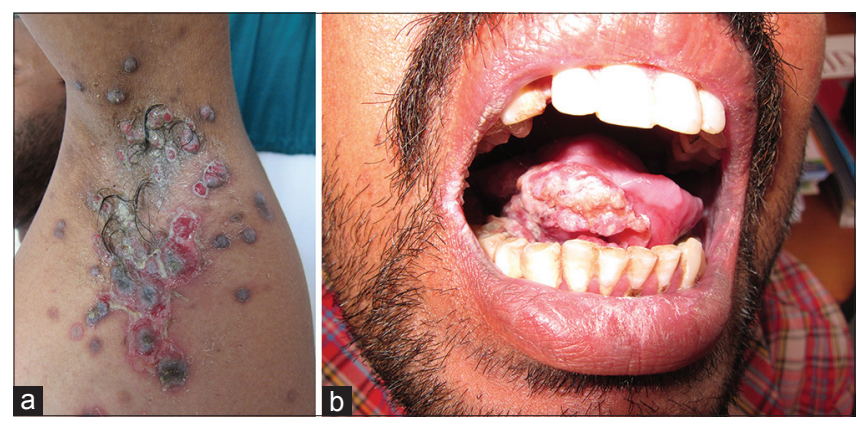

Figure 1: (a) Pemphigus vulgaris lesions in the axilla. (b) A growth on the right lateral margin of the tongue.

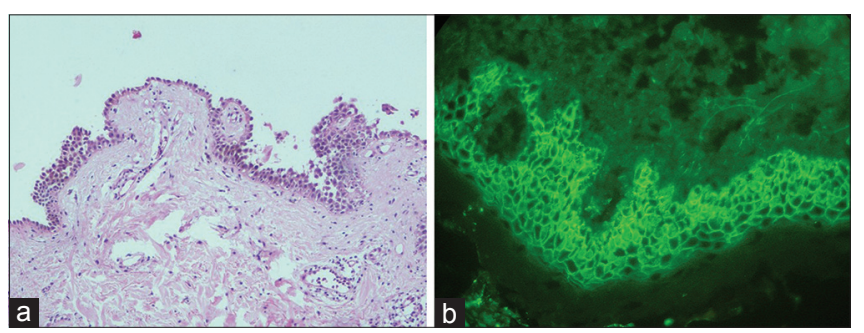

Figure 2: (a) Supra basal cleft and acantholytic cells in the lumen (hematoxylin and eosin staining, original magnification $\times 100$ ). (b) DIF showing intercellular deposits of IgG and C3c in the epidermis.

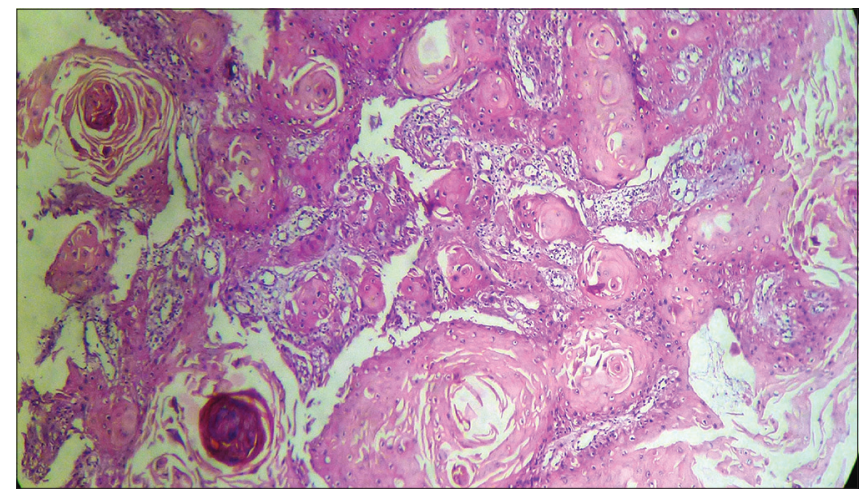

Figure 3: Well differentiated SCC (H\&E staining, original magnification $\mathrm{x} 100)$.

In the present case, the rare association between SCC and PV could be coincidental. But, it is possible to speculate that multiple factors like chronic mucosal damage, circulating anti DSG3 and DSG1 antibodies and subsequent loss of desmosomes, auto immunity, genetic factors might have contributed to carcinogenesis in the background of PV. However, large scale studies are warranted to establish the role of desmosomes and anti desmosomal antibodies in the pathogenesis of oral cancers and SCC of tongue.

\section{Consent}

The examination of the patient was conducted according to the Declaration of Helsinki principles. 


\section{www.odermatol.com}

\section{REFERENCES}

1. Faraci RP, Schour L, Graykowski EA. Squamous cell carcinoma of the oral cavity-Chronic oral ulcerative disease as a possible etiologic factor. J Surg Oncol. 1975;7:21-6.

2. Wong KC, Ho KK. Pemphigus with pemphigoid-like presentation, associated with squamous cell carcinoma of the tongue. Australas J Dermatol. 2000;41:178-80.

3. Kim J, Teye K, Koga H, Yeoh SC, Wakefield D, Hashimoto T, et al. Successful single-cycle rituximab treatment in a patient with pemphigus vulgaris and squamous cell carcinoma of the tongue and $\operatorname{IgG}$ antibodies to desmocollins. J Am Acad Dermatol. 2013;69:e26-7.

4. Inaoki M, Kaji K, Furuse S, Fujimoto A, Komatsu N, Takata M, et al. Pemphigus foliaceus developing after metastasis of cutaneous squamous cell carcinoma to regional lymph nodes. J Am Acad Dermatol. 2001;45:767-70.

5. Alaibac M. Targeting DSG3: from pemphigus to squamous cell carcinoma.Expert Opin Ther Targets. 2013;17:477-9.

6. Dusek RL, Attardi LD. Desmosomes: new perpetrators in tumour suppression. Nat Rev Cancer. 2011;11:317-23.

7. Maumi Y, Suzaki R, Ito N, Sawada M, Ishizaki S, Fujibayashi M, et al. Squamous cell carcinoma of the soft palate associated with autoantibodies to desmoglein 1 and 3. Dermatol Pract
Concept. 2013;3:55-7.

8. Chen YJ, Chang JT, Lee L, Wang HM, Liao CT, Chiu CC, et al. DSG3 is overexpressed in head neck cancer and is a potential molecular target for inhibition of oncogenesis. Oncogene. 2007;26:467-76.

9. Wang L, Liu T, Wang Y, Cao L, Nishioka M, Aguirre RL, et al. Altered expression of desmocollin 3, desmoglein 3, and beta-catenin in oral squamous cell carcinoma: correlation with lymph node metastasis and cell proliferation. Virchows Arch. 2007;451:959-66.

10. Narayana N, Gist J, Smith T, Tylka D, Trogdon G, Wahl JK Desmosomal component expression in normal, dysplastic, and oral squamous cell carcinoma. Dermatol Res Pract. 2010:649731.

11. Patel V, Martin D, Malhotra R, Marsh CA, Doçi CL, Veenstra TD, et al. DSG3 as a biomarker for the ultrasensitive detection of occult lymph node metastasis in oral cancer using nanostructured immunoarrays. Oral Oncol. 2013;49:93-101.

Copyright by Gandikota Raghu Rama Rao, et al. This is an open-access article distributed under the terms of the Creative Commons Attribution License, which permits unrestricted use, distribution, and reproduction in any medium, provided the original author and source are credited.

Source of Support: Nil, Conflict of Interest: None declared. 